\title{
PHD RESEARCH LEARNING IN PRODUCT ARCHITECTURE DESIGN
}

\author{
Sankowski, Olga (1); Otto, Kevin (2); Moon, Seung Ki (3); Krause, Dieter (1) \\ 1: Hamburg University of Technology; 2: Aalto University; 3: Nanyang Technological University
}

\begin{abstract}
The field of design research has been expanding into a wide diverse range of multidisciplinary topics. It takes substantial time for young researchers to attain a cumulative overview of state of the art on ever more complex methodologies. Teaching doctoral candidates in summer schools is an approach being taken by the design society to support them attaining an immersed understanding of a chosen research field as well as to help them formulate their own line of research. The aim for a new researcher is to form exchanges and collaborations with other researchers. The 'International Summer School on Product Architecture Design - PAD 2018' was such an effort, where 17 international PhD researchers and three international faculties met for a week and explored research in product architecture through hands-on exercises. We surveyed the researchers for effectiveness of the summer school and found that structure and concept of the summer school was effective for providing a background baseline of state of the art. We found there was a significant but less impact on individual participant's research. We have yet to understand if the creation of collaborations among participants will occur.
\end{abstract}

Keywords: PhD summer school, Product architecture, Design learning, Design methods

\section{Contact:}

Sankowski, Olga

Hamburg University of Technology

Institute of Product Development and Mechanical Engineering Design

Germany

o.sankowski@tuhh.de

Cite this article: Sankowski, O., Otto, K., Moon, S.K., Krause, D. (2019) 'PhD Research Learning in Product Architecture Design', in Proceedings of the 22nd International Conference on Engineering Design (ICED19), Delft, The Netherlands, 5-8 August 2019. DOI:10.1017/dsi.2019.59 


\section{BACKGROUND AND INTRODUCTION}

\subsection{Educational structure of doctoral degrees}

Across the international spectrum of the Design Society, there are different approaches taken to doctorate research and training. Traditional doctoral education in Germany has been described as a "master - apprentice model" (Kehm, 2004 \& 2005) or as an 'individual doctorate'. This model requires the doctoral students to do individual research and to produce a thesis usually while having a paid position within a research project or as an assistant for a professor. This type of doctorate demands a high amount of personal initiative and responsibility from the student, but also offers great flexibility. The associated professor, on the other hand, not only acts as a mentor and supervisor for the doctoral student, but also as the main examiner in the thesis defence.

In contrast, the American system has been referred to "'the gold standard' to which European universities aspire or should aspire" (Kehm, 2004, p.284). Here, doctoral education also includes formal coursework, which may also include laboratory work in the sciences. Programmes and schools for doctoral education with formalized procedures of supervision and examination are being established in many countries for this reason. However, in some of them structured programs are still not common; e.g. only $21 \%$ of German doctoral students in engineering participated in a program with structured coursework in 2015; 59 \% were not enrolled into a university (Hähnel and Schmiedel, 2016). In the American system, the trend is towards preparing $\mathrm{PhD}$ students for industrial careers by including elective courses in communication, management and/or accounting, beyond the narrowly focused and specific discipline (Vanderford, 2012; Carron, 2013).

In both systems however, the time to degree attainment is increasing (Altbach, 2004; Hüfner, 2004). One cause identified is "that knowledge has expanded and that it takes more time to impart the necessary skills (including ever more complex methodologies) to Doctoral students" (Altbach, 2004, p. 272). In this context, van de Schoot and colleagues (2013) examined the reasons for delay in doctoral completion of $\mathrm{PhD}$ candidates in the Netherlands and how organization and structure of doctoral education should be improved to shorten or even prevent delay. Among others they found that 1) working together with other PhD students as well as 2) an early clarification (in the first year) of the personal research question both decreases delay and overall time for $\mathrm{PhD}$ completion.

Against this background of $\mathrm{PhD}$ degree concerns, the Design Society offers a variety of summer schools in design for PhD students. The aim is to help students formalize their studies and research questions. In this paper, we review the summer school on Product Architecture Design, its structure and concept, and discuss its impact on PhD researchers in their pursuit of a doctorate degree.

\subsection{Doctoral summer schools}

Intensive courses for $\mathrm{PhD}$ research learning - usually referred to as summer or spring schools - have become more popular in recent years. At least four summer/spring schools for $\mathrm{PhD}$ candidates with Design Society sponsorship have taken place in the last two years (2017-2018), as indicated in the "past events" site of Design Society homepage in December 2018. Here, doctoral candidates from different universities and different nations come together, usually a few days and up to two weeks.

Blessing et al. (2005) reviewed a spring school course on design research, formulated to help $\mathrm{PhD}$ researchers form the personal study area. Design Research Methodology approach is presented and applied here. The spring school's concept and goals are general since no specific design research methods or topics are in the area of focus. A series of seminars conducted by the Nordic Network for Research on Communicative Product Design (Nordcode) from 2004 till 2008 (Keitsch, 2012) found that by providing a platform for discussing their ongoing research with peers and senior academics, students were able to improve their argumentation and reasoning skills. At the same time, collaborations between Nordic universities were encouraged. A detailed description of how an extensive design method, i.e. the Design Structure Matrix, can be applied in a short half-day workshop is described by Hölttä-Otto and colleagues (2018).

In summary, summer/spring schools can be mostly clustered into two types according to their goals. It is either a workshop on learning and applying general research skills that help with conducting research and completing a thesis, or it is a specific research area workshop course to teach state of the art research approaches in depth. Overall, we find a need for a comparison of summaries and 
evaluations of structure, teaching methods and outcomes of past summer school events. Here, we do this for the summer school on product architecture design (PAD 2018).

\subsection{Research questions}

In case of doctoral or PhD research learning in design, we agree with Margolin's view (2010) that, unlike the sciences, the social world is more difficult to form a cumulative overview of what has been done and researched already. Researchers in the same research field in design may not even agree on the same definitions of the terms they use, as shown by Gericke et al. (2017) in the case of 'design methods' and 'design tools'. This results in a diffuse and convoluted research area, making it difficult for doctoral candidates to contribute.

We hypothesize that doctoral summer schools for design research learning can help with this problem. By presenting and explaining state of the art and current approaches of special research topics in a deep and extensive manner, summer schools may support doctoral candidates in understanding these topics, thus, helping them to more quickly formulate their contributions to the field. Apart from local $\mathrm{PhD}$ programs and doctoral colleges young researchers from different countries can be brought together to learn design methods and tools and to discuss terms, definitions and findings. If this contributes to a network of researchers built up over time, we hypothesize that research questions and the creation of new design theories, tools, and practices can be addressed through this collaboration.

In this paper, we describe structure and concept as well as investigate the outcomes of international summer school on "Product Architecture Design - PAD 2018" and its effects on PhD students' research. Our specific research questions are:

1. Are structure and concept of the summer school effective in teaching doctoral students?

2. Is there a measureable impact on the doctoral candidates' research?

3. Can the summer school concept foster collaboration between participants?

To answer the research questions, a follow-up questionnaire was created and distributed five months later to participants. Design and results of the survey and also the conclusions derived from that will be explained as well.

\section{EDUCATIONAL APPROACH \& CONTENT OF THE PROGRAMME}

\subsection{Basic concept and organization of PAD 2018}

The PAD summer school held from Monday 4th to Thursday 7th June 2018 was the fifth event in this series. Its main idea is to bring young scientists together and to teach them current topics and approaches in PAD research, discuss gaps, and consider research extensions. The target group is doctoral candidates, usually in the second year of their $\mathrm{PhD}$ project, researching product architecture. During the summer school several research topics are discussed, i.e. particular methods or tools, using case studies of real products. Particular research topics are chosen for discussion, though topics are not the same over the years, but based on current research trends and problems in PAD.

The fifth PAD summer school took place at the Design Factory at Aalto University in Espoo, Finland. For the first time the event location was organized outside of Germany. In total seventeen doctoral candidates from six different countries participated; eight participants are affiliated to German universities, nine to universities from other nations. Four are female and thirteen male. The summer school was financially supported by different organizations; participation was therefore free of charge including workshop material, beverages, snacks, lunch and two evening events. Participation was further awarded with five ECTS credits.

Consistent with the findings of van de Schoot and colleagues (2013), main target group of fifth PAD 2018 were doctoral candidates not only in second year, but also in first year of their PhD project. An early an extensive overview and understanding of methods and approaches may help them to define their own research approach as soon as possible. In fact, nine participants were in the first year of the project at the time of the summer school (started in 2017 and 2018). Five were in second year (started 2016) and three were already working three years or longer on their research project.

\subsection{Educational approach and content}

The learning theory underlining the PAD summer school approach is based on the Kolb's learning theory of Wankat and Oreovicz (2015). According to that, students are exposed to a research problem 
through a hands-on exercise introducing the problem. Their attempt to solve it is reflected and theory and a method are derived from literature. We then have them make use of the method with higher success. In the final step of the Kolb's learning model, we reflect on the method's strengths and weaknesses. This begins the process of understanding the gaps and state of the art in PAD research. On a larger level, the overall learning theory is aimed at moving participants up Bloom's taxonomy (Wankat and Oreovicz 2015) over the course of the summer school week.

We assigned minimal pre-work and no out-of-class homework during the week. Participants were asked to prepare a short presentation about themselves, their research project and their connection to PAD research. Due to mixed completion levels in last summer schools, no further homework was assigned apart from the introduction in 2018.

The PAD 2018 started with a general introduction to product architecture design and state-of-the-art in modularity research. Each participant then introduced him- or herself in plenum, thus, giving the others an idea of the research topic and design approach they are working on. Next two days were dedicated to special topics in PAD research. In total four different topics were covered in the summer school with each a half-day workshop. Goal of these thematically oriented workshops were to teach doctoral candidates the presented methods and approaches and to improve their understanding of the topic through in-depth discussions with researchers from other countries. These four workshops are therefore located on the application and analysis level of Bloom's taxonomy. In an additional workshop on research gaps and new approaches to PAD (new concept in 2018), participants had to define their own research tasks based on their newly acquired knowledge (synthesis level). We then formed small groups to discuss their topics (evaluation level). The goal here was to promote collaboration between participants to work together on the creation of new design theories and tools.

\subsubsection{1st workshop on sustainable product architecture and platform assessment}

Content: The first workshop on Tuesday morning illuminated the aspect of sustainability and its importance for platform assessment. A sustainable platform has three characteristics: high sustainability, low risk to product redesign, and high commonality (Kim and Moon, 2017). For degree of sustainability, a single value can be aggregated out of three indicators that consist of environmental, economic, and social aspects. By comparing the sustainability value of two platform concepts, the more sustainable one can be selected based on the three indicators.

Structure: Using the case study involving a product family of vacuum cleaner robots, participants were assigned into two groups; one was estimating environmental sustainability using an eco-indicator tool, where material, manufacturing processes and weight of each part has to be added, and the other the social sustainability. Since no tool for social sustainability assessment is available, the second group spend their time on discussing social factors relevant to the product family of vacuum cleaner robots and how they could be measured in terms of customers' benefits. Results of the groups were then presented to each other and discussed in plenum.

Direct feedback of participants: They liked to discuss the influencing environmental and social factors that affect the sustainability. Some participants stated that it was hard to identify the connection of sustainability to modularity, which was probably due to the fact that they focused one step of the platform assessment method, as described by Kim and Moon (2017).

\subsubsection{2nd workshop on impact of modular product structures}

Content: This workshop is based on the idea of modularity being a gradual property of the product structure that can be defined through several properties, e.g. commonality or combinability, and characteristics, e.g. decoupling. These properties and characteristics of modularity on the other side have different effects in the life phases of a product (Hackl and Krause, 2017). For example, the characteristic "interface standardization" has a positive effect on manufacturing flexibility, which is an effect in the production life phase. The effects in the life phases have further an influence on economic target values, as in this case the lead time.

Structure: For the workshop, participants got an overview of all properties and characteristics of modularity as well as possible effects in two life phases. Split into two groups they discussed and analysed further positive and negative impacts of different properties and characteristics on effects. Results of the groups were then compared and discussed in plenum.

Direct feedback of participants: The participants enjoyed the deep discussions on the impact of modularity and the different properties and characteristics. They also wished for more time to discuss 
effects in more details. But they also had some difficulties to agree on particular effects, since some of the boundary conditions were not clear to them.

\subsubsection{3rd workshop on design-structure matrix}

Content: Concept and structure of the third workshop were adjusted a little bit to give participants more time to discuss alternative solutions. Topic of this workshop was the design structure matrix (DSM) and alternative ways to work with it. DSM is an adjacency matrix, where product architectures can be represented in terms of their single components and their relationships to each other. These relationships can be either binary or defined through the type of interaction, i.e. spatial, material, electrical energy, mechanical energy or information (Eppinger and Browning, 2012). By clustering components together that have a connection to each other, a modular structure can be derived.

Structure: Participants were asked to propose modularization concepts for a case study of a machineroom-less elevator and to suggest improvements in the architecture based on four prefilled DSMs given to them. The DSMs had a different level of detail (two matrices with high granularity and two with low; at each level of detail one matrix was binary and the other reflecting different types of interaction) (Hölttä-Otto et al., 2018). Participants were free to choose one of the DSMs that they perceived more interesting or convenient for their approach. Results of the groups were then presented and the different approaches discussed in plenum.

Direct feedback of participants: The participants enjoyed the freedom to choose their own approach and see how the method works, but also its limits. For example, the lack of visual support for the matrix was mentioned in this context.

\subsubsection{4th workshop on method validation with the example of life phase modularization}

Content: The overall goal of this workshop was to accomplish a new validation approach of a method step based on former experimental research experiences (Üreten and Krause, 2017). The example of use was the life phase modularization, a method within the integrated PKT-approach (Krause et al., 2014), enriched by a method adaption realised through a consistent model-based support (Hanna et al., 2018). Herein, representatives of each product life phase (e.g. purchase, production, service) come together to discuss different and eventually opposing modularization goals and to compromise for the best overall solution. To support discussions of experts with different backgrounds, two visual tools are used here (i.e. network plan and module process chart).

Structure: For the workshop, participants were split into two groups, one prepared the results using Cameo Systems Modeler (a model-based systems engineering tool) which allows consistency and traceability and the others used posters (conventional approach) allowing an immediate working without specific software knowhow. By presenting both approaches participants were able to compare and discuss advantages and disadvantages of both.

Direct Feedback of the participants: Both groups mentioned the strategic view on modularization to be particularly positive. Potential for improvement of the life phase modularization method was identified through the feedback given by the participants. These include - besides subject matter oriented recommendations - hints for organizational conditions and modern teaching concepts.

\subsubsection{Last workshop on research gaps and new approaches to PAD}

Content: Based on their newly gained knowledge and current research interests, participants were asked in the last workshop to come up with research gaps and new ideas in the field of PAD. The workshop therefore started directly with a brainstorming, without any thematically introduction.

Structure: Participants wrote their ideas on cards and pinned them on a wall. Ideas and research gaps were then assorted and clustered into definite research topics. Finally, each participant chose the most interesting research topics for him/her. According to that participants split into groups of two up to four, performed a search on state of the art in the research area of interest as well as discussed and elaborated ideas for possible design and research approaches. Findings were summarized by each group in a short presentation and then discussed in plenum. Goals of this workshop were to give participants new ideas for their own research and also to foster research collaboration of $\mathrm{PhD}$ candidates.

Direct feedback of participants: Participants enjoyed the exchange of research ideas and some claimed they got new ideas for their own research topic as well. Several participants wished for more time to discuss ideas or even to start this kind of research exchange already earlier in the summer school. 


\section{FOLLOW-UP QUESTIONNAIRE}

\subsection{Survey design}

During the summer school feedback was gathered verbally for all workshop parts and also at the end of each day. It was documented immediately and directly on a whiteboard. Additionally to this immediate and direct feedback a short follow-up questionnaire was distributed five months later. Its goal was to elicit information about the overall impression of the PAD summer school after some time has passed as well as to measure the impact of the summer school on the individual participant's research and networking. Since the group of participants is quite small $\left(\sum=17\right)$ and their demographic distribution well known to us, we dispensed with including questions on demographics in terms of data privacy. In total 26 questions clustered into five thematically question blocks have been distributed to participants. Four types of questions were used:

- A six point Likert-type scale was used to measure attitudes, i.e. levels of agreement/ disagreement, directly. An even number of choices doesn't allow for neutrality; respondents must therefore choose a positive or negative answer.

- Rank order questions with two conditional options and a neutral one ('more of A with less of B', 'more of B with less of A' or 'ratio of A to B is just right') were used to evaluate which parts of the summer school were more valuable for participants.

- A dichotomous question type ('yes'/'no') was used for unambiguous questions.

- Open-ended questions at the end of all question blocks were selected to extract further comments and overall feedback from participants.

\subsection{Results of survey}

In the following response overviews (figures 1-3) for each question the cumulative answers are stacked upon each other. Agreement to a question is visualized through shades of green and disagreement through shades of red; transition is further emphasized through a green line (for black and white print). For the evaluation we match questions and results with the research questions stated above. In total, 13 out of 17 participants responded to the survey.

\subsubsection{Questions regarding general contents and outcomes of the summer school}

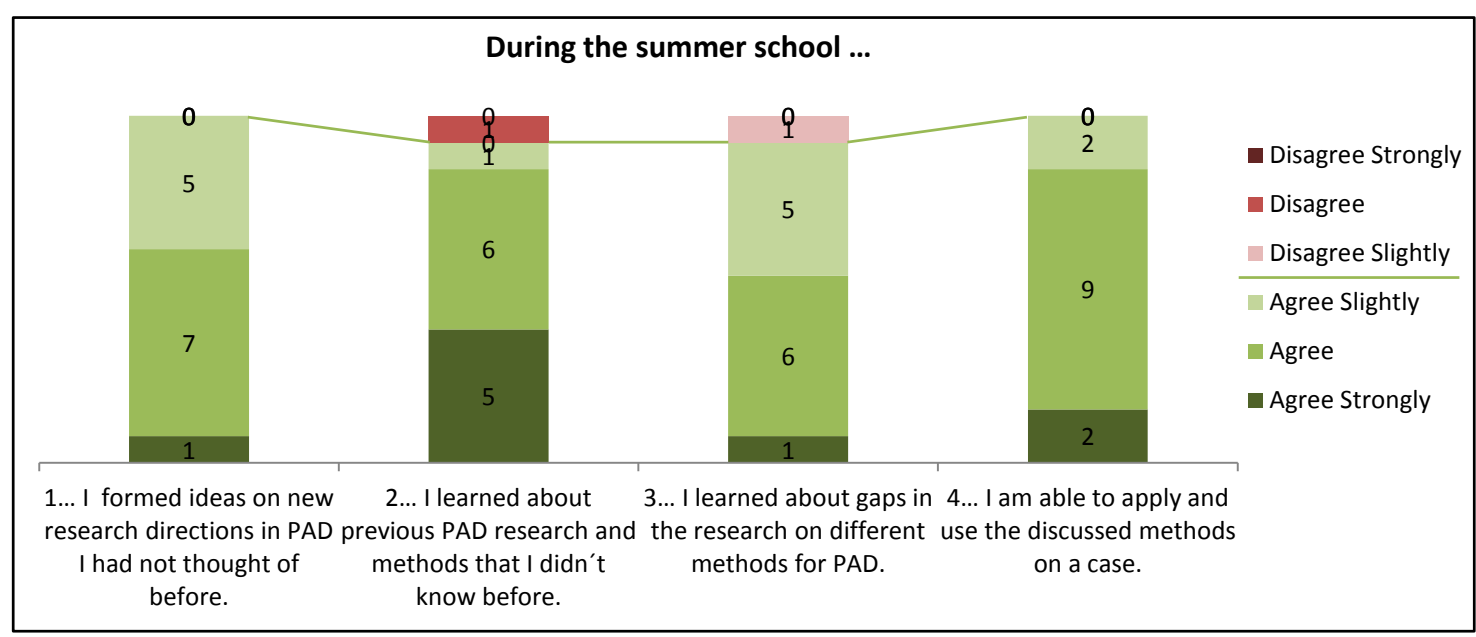

Figure 1. Response overview for first question block

This part primary seeks to answer the first research question, whether the summer school was successful in teaching new topics (i.e. research directions, PAD methods, research gaps, application of methods). We did not ask for particular workshops and their outcome. First, this has been done during summer school week; second, particular workshop topics change every time, we therefore would not be able to derive improvements from that.

Response overview is shown in figure 1. Only one stated that he/she did not learn new methods at PAD summer school and one person also disagreed on learning about research gaps in PAD methods. These two statements came not from the same person. Additionally, one comment was recorded here: 
"What I liked particularly is that I got a good overview and understanding of the field without having specific knowledge in the field in the beginning."

\subsubsection{Questions regarding individual outcome}

Questions were related to the second research question asking whether the summer school affected the participants' research. Agreements on the first four statements are quite high, while agreement on last statement 'changed research focus due to participation' is significantly low. In a comment one of the participants, who disagreed on statement number 5, gave more insights to the impact on his/her research: "I have not changed my focus after the summer school inputs, but I got confirmation from different stakeholders for my work. This is motivating. [...]". None of the participants disagreed on more than two statements.

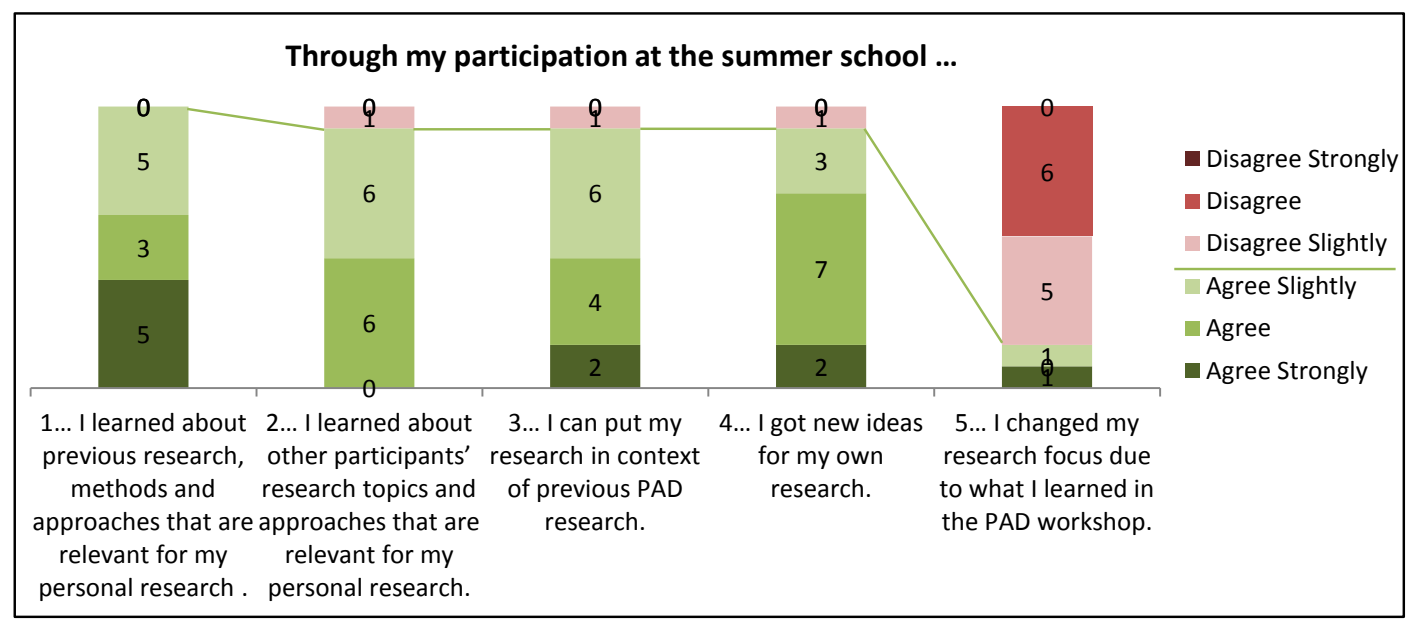

Figure 2. Response overview for second question block

\subsubsection{Questions regarding scheduling of the summer school}

Additionally to the research questions stated above, feedback for the overall concept of the PAD summer school and for the different parts in it (e.g. talking about own research, learning new methods, discussing research gaps) were gathered to derive improvements for the overall (learning) concept of the summer school. Responses on this part vary greatly; e.g. distribution of those who would like to talk more about PAD in general and those who would like to focus more on methods and approaches instead is equal (4-4). The rest preferred to leave the concept as it is (5). Equal distributions were also found for 'more or less personal research coverage' and 'discussions on more or less methods'. Without significant preferences on one part or the other, actions for future summer school concepts can be hardly derived. Since this part of the survey does not directly address the research questions from above but the future improvements for the summer school, we don't go any deeper into details here.

\subsubsection{Questions regarding networking potential}

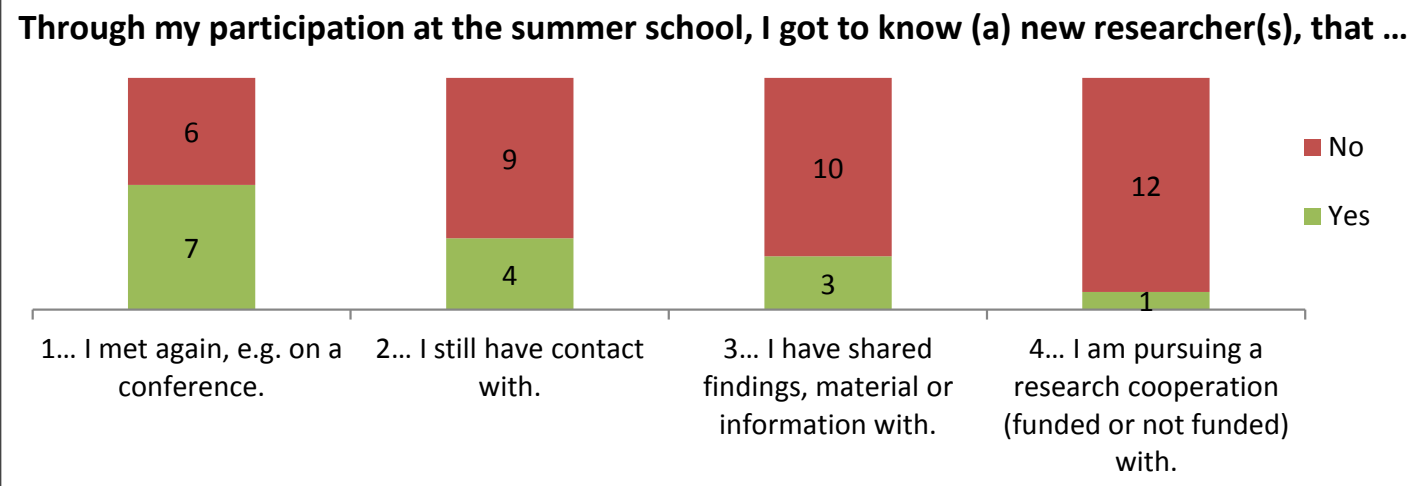

Figure 3. Response overview for fourth question block 
Here we asked whether the summer school had impact on participants' research network (research question 3). Questions of the fourth question block reflect an increasing degree of possible networking between participants (figure 3). As expected, number of positive responses decrease from statement 1 to 4. Only four participants, who met through PAD summer school, still have contact to each other, only three shared further research material after the summer school, only one stated to pursue research cooperation to another participant. We would expect an even number of positive responses for this statement, but since not all participants responded to the survey, there is no evidence of a wrong entry. However, it does not prove the existence of an actual research network resulted from PAD summer school either.

\subsubsection{General questions and overall feedback}

This last part aimed at answering the questions, if the participants would recommend the summer school to other researchers and PhD students (yes: 13, no: 0) and if they are still working in the field of PAD (yes: 9, no: 4). It is a very positive result that all participants would recommend PAD summer school to other fellow researchers working in the field of PAD. Interestingly, one of those participants, who are not working in the field of PAD anymore, also was the person, who strongly agreed that his/her research focus changed due to summer school participation. Additionally to the dichotomous questions, the overall feedback was also gathered here (positive: 7; negative: 8). A section of the comments, showing the diversity of feedback, is summarized in table 1.

Table 1. Overall feedback from survey (not complete)

\begin{tabular}{|c|c|}
\hline $\begin{array}{l}\text { At the summer school I enjoyed/ I liked the } \\
\text { most: }\end{array}$ & I would like, if the summer school improved: \\
\hline "[...] The Overview of research on PAD" & $\begin{array}{l}\text { "More general information about PAD } \\
\text { techniques" }\end{array}$ \\
\hline $\begin{array}{l}\text { "The scientific exchange between the different } \\
\text { nationalities." }\end{array}$ & $\begin{array}{l}\text { "More Information in advance. Like Paper or } \\
\text { Book recommendations to prepare" }\end{array}$ \\
\hline $\begin{array}{l}\text { "[...] All in all, I enjoyed the discussions the } \\
\text { most." }\end{array}$ & $\begin{array}{l}\text { "The amount of focus on trialing (sic) certain } \\
\text { methods or systems. [...]" }\end{array}$ \\
\hline $\begin{array}{l}\text { "The summer school is a great opportunity to } \\
\text { talk about research [...] Different perspectives } \\
\text { support creativity and coming up with new } \\
\text { ideas. [...]" }\end{array}$ & $\begin{array}{l}\text { "[...] It would be great if besides this "kickoff" } \\
\text { (sic) follow-up meetings are offered officially. } \\
\text { More focus on personal research would be great. } \\
{[\ldots] "}\end{array}$ \\
\hline $\begin{array}{l}\text { "[...] Furthermore I liked that it was apparently } \\
\text { not only for PAD "deep divers" but also } \\
\text { engineering design researchers which didn't had } \\
\text { a deep specific knowledge at the beginning of } \\
\text { the summer school." }\end{array}$ & $\begin{array}{l}\text { "[...] The output of the discussion on research } \\
\text { gaps should be more specific }[\ldots] . \text { It would be } \\
\text { nice, if the last step was the forming of groups } \\
{[\ldots], \text { which then plan a project for themselves, }} \\
\text { including next steps, rough timeline etc. }[\ldots] "\end{array}$ \\
\hline
\end{tabular}

\section{CONCLUSIONS FOR RESEARCH QUESTIONS}

\subsection{Effectiveness of teaching}

Concluding from feedback during the event as well as the survey results (i.e. answers on question block 1 and comments), we can see that the concept, structure and content of the course as a whole were effective in teaching PhD researchers. We see three main reasons for this outcome: First, the content made the program good; $\mathrm{PhD}$ researchers were interested in fully understanding methods. The research literature and the hands-on exercises with a small set of demonstrators (e.g. product family of vacuum cleaner robots) provided direct experience to understand what they can and cannot do. Second, the instructors were strong and knowledgeable in the research field. And third, the application of the learning models, i.e. every research topic addressed in the course was supported by an exercise and participants were always encouraged to analyse and discuss results.

Even though, participants' distributions were quite diverse in terms of affiliation and year of $\mathrm{PhD}$ project, no effects on learning outcome could be detected resulting from that. We further conclude that $\mathrm{PAD}$ summer school is also suitable for first year $\mathrm{PhD}$ candidates, who are in the process of defining their research question, as well as for those, who already have a good overview of the research area. 
However, it should be considered that we did not ask, if participants are still able to perform the methods taught during the four workshops or if they can "only" put them in context to each other.

\subsection{Impact on individuals' research}

Due to summer school participation we can see an effect on the participants' personal research. It gives them additional drive to their research, e.g. new ideas and related topics, but probably does not have significant impact on the topic itself. We believe that not a particular part of the summer school, but all the research related discussions during group work or in plenum had this effect on individuals' research. However, more detailed questioning of the type and amount of influence on personal research is necessary to enhance quality of results here, e.g. asking if research focus was confirmed due to insights gained from participation and not only if it changed.

The fact that the same person who strongly agreed that his/her research focus changed due to summer school participation is not working in the field of PAD anymore, let us question if the PAD summer school could actually have a negative effect on individual participant's research. However, changing of research field could also result from other non-related incidents, e.g. new/different research project.

\subsection{Collaboration between participants}

The most ambitious goal of the summer school, i.e. to foster research collaboration between participants, could not be achieved; at least not five months later (time of questionnaire distribution). Even though design and structure of last workshop on research gaps as well as the whole summer school itself was rated very positive, it was not successful in creating strong research networks between participants. However, this should be further tracked if possible.

\section{OVERALL CONCLUSIONS}

Popularity of summer/spring schools in the context of $\mathrm{PhD}$ research learning seems to be high and increasing. Unfortunately, there is no cumulative database for past events summarizing contents and teaching concepts as well as presenting evaluations of outcomes. More published data and information here could enhance quality of future summer schools, making it easier to learn from each other.

In context of the sheer amount of contributions published daily and the increasing complexity and fuzziness of the design research field itself also relevance of such summer schools is growing. To see the big picture and understand how other researchers from other countries and other research fields think and which wording they use, we have to bring them together and to foster international and transdisciplinary exchange and collaboration. In case of future PAD summer school, this may be achieved through a more holistic approach, i.e. research exchange of participants earlier at the event, clustering of participants into groups according to their research topic or research approach, and/ or by giving them more research tasks. To improve the collaboration, a communication channel between the participants should be established through social media or an online tool after the event. In either way, outcomes of future summer schools should be measured to make the effect of changes clear.

Another general finding is also that doctorate students should be taught in diverse topics and skills, i.e. how to do design research and the current state in their research field from different point of views. One possible improvement lies therefore in merging these summer school concepts together, while also keeping a diversity of research topics.

Overall, the PAD summer school 2018 was verified to be successful in achieving most of its goals, a validation of its structure, concept and teaching methods, however, cannot be derived on basis of the data. First, we miss evaluations from other summer schools or similar courses for comparison. Second, sample size of participants and feedback data is too small. Risk of listening to too much or too less to one particular statement is therefore high. Diversity of wishes and opinions of participants can be seen e.g. in the mixed answers we got regarding the overall structure and scheduling of the summer school (section 3.2.3). Feedback is still valuable for future planning of PAD summer school, but should be questioned, discussed and compared to each other to ensure actual improvements to the course.

\section{REFERENCES}

Altbach, P.G. (2004), “The United States: present realities and future trends", In: Sadlak, J. (Ed.), Doctoral studies and qualifications in Europe and the United States: Status and prospects, UNESCO, Bucharest, pp. 259-277. 
Blessing, L. and Andreasen, M.M. (2005), “Teaching engineering design research”, Engineering Design. Theory and practice: A symposium in honour of Ken Wallace, Engineering Design Centre, University of Cambridge, pp. 32-41.

Carron, L. (2013), "The changing PhD: How can higher education institutions prepare science PhDs for alternate careers", In Progress. http://inprogressjournal.net/archives/current-issue-2/the-changing-phd-how-canhigher-education-institutions-prepare-science-phds-for-alternate-careers/

Eppinger, S D. and Browning, T. R. (2012), Design structure matrix methods and applications, MIT press, London, England.

Gericke, K., Eckert, C. and Stacey, M. (2017), “What do we need to say about a design method?”, 21st International Conference on Engineering Design (ICED17), Vol 7: Design Theory and Research Methodology, Vancouver, Canada, August 21-25, pp. 101-110.

Hackl, J. and Krause, D. (2017), "Towards an Impact Model of modular Product Structures“, 21st International Conference on Engineering Design (ICED17), August 21-25, 2017, Vancouver, Canada, pp. 151-160.

Hähnel, S. and Schmiedel, S. (2016), Promovierende in Deutschland, Destatis. Available at: https://www.destatis.de/DE/Publikationen/Thematisch/BildungForschungKultur/Hochschulen/Promoviere nde.html (13.12.2018).

Hanna, M., Schwede, L.-N. and Krause, D. (2018), "Model-based consistency for design for variety and modularization”, 20th International DSM Conference (DSM 2018), Trieste, Italy, pp. 239-248.

Hölttä-Otto, K., Niutanen, V., Eppinger, S., Browning, T. R., Stowe, H. M., Lampinen, R., and Rahardjo, A. (2018), "Design sprint for complex system architecture analysis". Proceedings of the ASME 2018 International Design Engineering Technical Conferences and Computers and Information in Engineering Conference (IDETC2018), August 26-29, 2018, Quebec City, Quebec, Canada.

Hüfner, K. (2004), “Germany”, In: Sadlak, J. (Ed.), Doctoral studies and qualifications in Europe and the United States: Status and prospects, UNESCO, Bucharest, pp. 51-61.

Kehm, B.M. (2004), "Developing Doctoral Degrees and Qualifications in Europe: Good Practice and Issues of Concern -A Comparative Analysis", In: Sadlak, J. (Ed.), Doctoral studies and qualifications in Europe and the United States: Status and prospects, UNESCO, Bucharest, pp. 279-298.

Kehm, B.M. (2005), "Forces and forms of change: Doctoral education in Germany within the European framework", International conference on "Forces and Forms of Change in Doctoral Education Internationally” organised by CIRGE, University of Washington, August (unpublished manuscript).

Keitsch, M. M. (2012), "The nordcode network: a scandinavian approach to doctoral education in design”, Proceedings of the 14th International Conference on Engineering \& Product Design Education (E\&PDE12) Design Education for Future Wellbeing, Antwerp, Belguim, September 6-9, pp. 705-710.

Kim, S. and Moon, S.K. (2017), "Sustainable platform identification for product family desig", Journal of Cleaner Production, Vol. 143, pp. 567-581. http://dx.doi.org/10.1016/j.jclepro.2016.12.073.

Krause, D., Beckmann, G., Eilmus, S., Gebhardt, N. and Jonas, H. (2014), "Integrated development of modular product families: a methods toolkit”, In: Simpson, T.W., Jiao, J.R., Siddique, Z. and Hölttä-Otto, K. (Ed.), Advances in Product Family and Product Platform Design, Springer-Verlag, New York, pp. 245-269. https://doi.org/10.1007/978-1-4614-7937-6.

Margolin, V. (2010), "Doctoral education in design: problems and prospects”, Design Issues, Vol. 26 No. 3, pp. 70-78. https://doi.org/10.1162/DESI_a_00031.

Üreten, S. and Krause, D. (2017), "Discursive vs. intuitive - An experimental study to facilitate the use of design catalogues", 21st International Conference on Engineering Design (ICED17), Vol. 9: Design Education, Vancouver, Canada, August 21-25, pp. 99-108.

van de Schoot, R., Yerkes, M. A., Mouw, J. M., and Sonneveld, H. (2013), "What took them so long? Explaining PhD delays among doctoral candidates", PloS one, Vol. 8 No.7, e68839. https://doi.org/10.1371/journal.pone.0068839.

Vanderford, N.L. (2012), "Broadening PhD Curricula”, Nature Biotechnology, Vol. 30 No.1, pp. 113-114. https://doi.org/10.1038/nbt.2091

Wankat, P.C. and Oreovicz, F.S., (2015), Teaching engineering, Purdue University Press.

\section{ACKNOWLEDGEMENTS}

We wish to acknowledge the effort by all that took part in organizing the PAD summer school 2018 as well as all the participants that made it a success and also shared their feedback and insights with us. We offer a sincere thanks to the Design Society and Aalto University for supporting PAD summer school. Also a thanks to the financial help of Aalto University and the free use of their premises and material, we were able offer participation at PAD summer school without charges. A special thanks to the German Academic Exchange Service (DAAD) and the Academy of Finland for supporting cooperation between Hamburg University of Technology and Aalto University. 